\title{
A CONTRIBUIÇÃO DO PENSAMENTO DIALÉTICO DE HENRI LEFEBVRE PARA A PESQUISA INTERDISCIPLINAR SOBRE A QUESTÃO URBANA
}

\author{
THE CONTRIBUTION FROM HENRI LEFEBVRE'S DIALECTICAL \\ THINKING FOR INTERDISCIPLINARY RESEARCH ON URBAN ISSUES
}

Teresinha Maria Gonçalves ${ }^{1}$

\begin{abstract}
Resumo
Este artigo é uma reflexão sobre as possibilidades do pensamento de Henri Lefebvre para a compreensão da realidade urbana, hoje resgatando nele o pensamento marxista e a visão dialética de mundo e sociedade. Lefebvre apresenta o fenômeno urbano como um espaço criado no âmbito da produção industrial, trazendo implícitas as contradições da sociedade industrial e as consequências destas na organização e configuração do espaço urbano. $\mathrm{O}$ interesse pela obra de Lefebvre decorre por motivos acadêmicos e político-sociais. A autora coordena um grupo de pesquisa sobre o espaço urbano há 12 anos, no âmbito do Programa de Pós-Graduação em Ciências Ambientais da Universidade do Extremo Sul Catarinense, Brasil, de onde surgem pesquisas sobre a cidade e o espaço urbano, tanto do grupo como de mestrandos e doutorandos. $\mathrm{O}$ GIPMAUR (Grupo Interdisciplinar e Interinstitucional de Estudos e Pesquisas sobre Meio Ambiente e Espaço Urbano) trabalha numa perspectiva interdisciplinar em que várias ciências tentam dialogar sobre a questão urbana. O conceito de totalidade implícito no método dialético é uma perspectiva estratégica no enfrentamento da fragmentação dos estudos urbanos e vem colaborar para a construção de uma metodologia de trabalho interdisciplinar. O estudo enfatiza a concepção de Lefebvre sobre espaço social, tecido urbano e vida cotidiana.
\end{abstract}

Palavras-chave: realidade urbana; pensamento dialético; espaço social; vida cotidiana; interdisciplinaridade.

\begin{abstract}
This article is a reflection on the possibilities of Henri's Lefebvre thinking, for the comprehension of the urban reality in now days, rescuing in the author the Marxist thinking and the dialectic vision of the world and the society. Lefebvre shows the urban phenomenon as a space created in the field of industrial production, bringing implicit contradictions of industrial society and the consequences behind the organization an the urban space. The interest in Lefebvre's work was born by academic an socio-political issues. The writer of this article has coordinates a research group of urban space for 10 years, in fields of post-graduate programs in environmental sciences at the Santa Catarina's Extreme South University, Brazil, place where research of the city and the urban space have raised in both master and doctorate programs. The GIPMAUR (the Interdisciplinary and Interinstitutional Group of Studies and Investigations of the Environment and the Urban Space) works in a interdisciplinary perspective where various sciences attempt to dialogue on urban issues. The whole concept implicit in the dialectical method is a strategic deal facing the fragmentation of the urban studies and
\end{abstract}

\footnotetext{
${ }^{1}$ Universidade do Extremo Sul Catarinense - UNESC. Endereço: Rua João Cechinel 536 - apto 301 Bairro Pio Correa - CEP: 88811-500 - Criciúma/SC - E-mail: tmg@ unesc.net
} 
contributes to the construction of a methodology for interdisciplinary work. The study emphasizes Lefebvre's conception of social space, urban fabric and daily life.

Keywords: Urban reality; dialectic thinking; social space; daily life; interdisciplinarity.

\section{INTRODUÇÃO}

\section{A pesquisa interdisciplinar e o método dialético}

Toda pesquisa está ancorada numa posição teórica. O lugar teórico esclarece a visão de mundo do pesquisador, sua concepção de sujeito, sua visão de ciência e até seu comprometimento político-social.

A pesquisa interdisciplinar busca o diálogo entre vários saberes. O conhecimento científico origina-se de experimentos e observações conscientemente controlados, repetidos e testados depois de um período marcado pela concentração e pela especialização disciplinar, diante de complexidades antes não percebidas e pela inadequação de procedimentos para enfrentá-las.

A perspectiva interdisciplinar e o Movimento Transdisciplinar surgem com o intuito de superar o presente quadro disciplinar. Esse movimento pode levar à redefinição de métodos e práticas de pesquisa para enfrentar novos problemas vigentes no tempo atual. O pensamento dialético pode contribuir com esse movimento, porque o lugar de onde parte é um lugar integrador a partir do movimento dialético da realidade.

A prática do GIPMAUR tem demonstrado que o diálogo de saberes pretendido só é possível pelo enfrentamento das contradições dos vários saberes envolvidos para se entender determinadas realidades. O real, o problema de pesquisa, constitui-se, assim, em um elemento integrador desses vários saberes, pois para ele convergem os olhares das várias ciências envolvidas na mesma pesquisa.

O mesmo acontece com as ciências da natureza. Um biólogo, por exemplo, poderá pensar que sua tarefa, numa pesquisa para arborização de uma cidade, esgota-se quando ele termina o levantamento florístico ou o levantamento da fauna urbana. $\mathrm{Na}$ perspectiva dialética, ele irá interagir com os demais integrantes de sua equipe e se interessar em saber as estratégias metodológicas e os resultados da pesquisa de representação social sobre a arborização que seus colegas psicólogos fazem e vice-versa ou se interessar pelos métodos que seu colega geógrafo utiliza para analisar o clima de uma cidade. Indo mais além, irá interessar-se pelas condições sociais das pessoas que moram no entorno da praça. 
Infelizmente, as ciências naturais estiveram muito afastadas dessa visão mais ampla de pesquisa, fechando-se em laboratórios. Hoje, com a prática da interdisciplinaridade, essa postura está, embora lentamente, modificando-se (GOLDENBERG, 2005).

O método dialético é uma ferramenta importante para o trabalho investigativo interdisciplinar. A realidade pensada dialeticamente privilegia a concepção do todo.

A noção de totalidade vem, então, contribuir para que os diferentes saberes possam dirigir seu olhar para o objeto de estudo, que é a realidade concreta, resultado de múltiplas determinações e historicamente construída.

No entanto, não existe uma única concepção de dialética. Há concepções contraditórias e divergentes. Nossa concepção de dialética considera que o método dialético é orientado por princípios do materialismo histórico e do materialismo dialético e se configura como totalidade-contradição-movimento.

Considera-se como princípio dessa lógica:

1- Pressuposto do conflito: toda formação social é contraditória para ser historicamente superável. A superação se daria pelo movimento interno de tese-antítese e síntese. Toda formação social é histórica e está sempre em transição. Isso leva à suposição de que a realidade social é dinâmica na sua produtividade histórica. Dessa forma, a dialética está ligada à historicidade da realidade social.

2- A totalidade dialética: para se entender o princípio de totalidade na dialética na trilogia tese-antítese e síntese, há que se ter a compreensão da dinamicidade da realidade tanto social quanto natural. Para Demo (1989), é uma duologia, porque da síntese sempre se construirá a próxima tese.

3- Condições objetivas e subjetivas: segundo Demo (1989), as condições objetivas são aquelas dadas externamente ao homem; e as subjetivas, aquelas que dependem da opção humana. Exemplos: a divisão em gênero, a desigualdade social, as necessidades materiais, a ambiência física e ecológica são condições objetivas. Discorda-se dessa concepção do autor, pois a questão assim colocada se refere ao geral e ao particular, uma divisão cartesiana da realidade. Nas condições objetivas estão incluídas as subjetividades dos sujeitos.

Numa concepção mais crítica, pode-se afirmar que as condições objetivas são dadas pelas subjetividades dos sujeitos que compõem uma sociedade. A sociedade se movimenta num paradigma de intersubjetividades (HABERMAS, 1990). Na sociedade concreta estão as condições imateriais dadas pelos valores, pela cultura e pela história. 
Para se compreender a realidade urbana, precisamos levar em conta que as contradições da sociedade aí se expressam. O método dialético, então, contribui para que os investigadores do urbano e da cidade vejam os problemas urbanos como fenômenos complexos e, como tal, demandem investigações que não fragmentem os estudos e, dessa forma, não produzam, também, conhecimentos fragmentados.

\section{INDUSTRIALIZAÇÃO E URBANIZAÇÃO}

$\mathrm{Na}$ perspectiva de Lefebvre (1991b), para se compreender a problemática urbana, é necessário um ponto de partida. Esse ponto de partida seria o processo de industrialização, indutor dos problemas urbanos relativos ao crescimento e à planificação, que afetou o desenvolvimento da realidade urbana.

A industrialização caracteriza a sociedade moderna, o que vale dizer que a sociedade moderna é a sociedade industrial. Desse modo, a industrialização se constitui como ponto de partida da reflexão sobre a época contemporânea. Faz uma inflexão sobre a cidade que preexiste antes dela.

Segundo Lefebvre (1991b), as criações urbanas, as obras mais belas da vida urbana, datam de épocas anteriores à industrialização. A cidade oriental - ligada ao modo de produção asiático -, a cidade arcaica (Grega ou Romana) e a cidade Medieval - inseridas nas relações feudais - sempre tiveram o objetivo, quase que intuitivo, de criar o aglomerado, o coletivo. E na criação desses territórios nasce o caráter político da cidade e suas características comercial, artesanal e bancária. A esses territórios agregaram-se mercadores nômades, que estavam relegados para fora da cidade.

Para Lefebvre (1991b), a industrialização começa quando nasce o capitalismo concorrencial com a burguesia especificamente industrial. Nesse momento, a cidade já é uma poderosa realidade.

Para o autor, a partir do subproduto crescente da agricultura, em detrimento dos feudos, as cidades começam a acumular riquezas tais como objetos, tesouros e capitais virtuais. Já existe nesses centros urbanos uma grande riqueza monetária obtida pela usura e pelo comércio. Neles prospera o artesanato, produção bem distinta da agricultura. As cidades apoiam as comunidades camponesas e a libertação dos camponeses e se aproveitarem disso em seu próprio benefício, pois são centros de vida 
social e política onde se acumulam não apenas as riquezas como também os conhecimentos, as técnicas e as obras (Obras de artes, Monumentos).

A própria cidade é uma obra e isso contrasta com a orientação irreversível na direção do dinheiro, do comércio, das trocas, na direção dos produtos. Nesse sentido, a obra é o valor de uso e o produto é o valor de troca. Os espaços públicos das cidades, ou seja, as suas ruas, as suas calçadas e as suas praças, os seus edifícios e os seus monumentos, para Lefebvre, são a FESTA, que consome improdutivamente, sem nenhuma outra vantagem, além do prazer e do prestígio, enormes riquezas em objeto e dinheiro.

Enquanto os ricos das cidades medievais preocupam-se em ostentar um cenário urbano com grandes edificações e concretude, centralizando as riquezas, o capitalismo comercial e bancário torna a riqueza móvel, estabelecendo circuitos de troca e redes de transferência de dinheiro. Quando a industrialização começa, a riqueza deixa de ser predominantemente imobiliária, assim como a produção agrícola e a propriedade da terra. As cidades começam a ter foco com os capitalistas urbanos enriquecidos pelo banco e pelo comércio. Elas sobrevivem e se fortalecem ao se constituírem em redes de cidades com uma certa divisão do trabalho, tecnicamente, politicamente e socialmente falando.

De acordo com Lefebvre (1980), esse sistema urbano não chegou a se instalar. Entra em cena o Estado, com seu poder centralizador e egoísta, individual. As cidades começam a se sobrepor umas às outras e a organização do espaço urbano começa a seguir a lógica da acumulação e da concorrência. A cidade predomina, no entanto, não é mais como na antiguidade, a Cidade-Estado. A tríade cidade-sociedade-Estado são três termos que se distinguem. A morfologia social da cidade se modifica, mas conserva o caráter orgânico da comunidade, herança da aldeia, que se traduz na organização corporativa. Segundo Lefebvre, a vida comunitária em nada impede a luta de classes.

O sistema urbano, termo utilizado pelo autor, nasce no bojo da passagem do capitalismo comercial para o capitalismo bancário (LEFEBVRE, 1991a). Essa passagem não foi tranquila, fez-se acompanhar de uma gigantesca crise, ou seja, enquanto diversas indústrias se instalam esporadicamente e dispersas, a tecelagem, a metalurgia e a extração de carvão, indústrias nascentes, implantam-se fora, na periferia das cidades, perto das fontes de energia (os rios, a floresta e o carvão), dos meios de transporte, das matérias-primas e de uma certa mão de obra já qualificada vinda de tecelões, ferreiros e outros tipos de artesãos. 
Essa espacialidade da cidade é então alavancada pelo tipo de indústrias que vão surgindo. Ao mesmo tempo, as velhas cidades concentram o poder, o dinheiro, os negócios, as residências dos dirigentes políticos e econômicos e as reservas de mão de obra. Para Lefebvre, a cidade tal como a fábrica concentra os meios de produção em pequenos espaços. Dessa forma, não é mais interessante para os empresários a indústria fora da cidade. Sob esse ponto de vista, a cidade, ao comprimir o espaço com inúmeros e múltiplos serviços, desempenhou um papel importante no processo de industrialização. "Desde então, a indústria deveria produzir seus próprios centros urbanos, cidades, aglomerações industriais ora pequenas (Le Creusot), ora médias (Saint-Etienne), às vezes gigantes (Ruhr, considerada conurbação). Seria necessário" (LEFEBVRE, 1991a, p. 8).

A indústria toma de assalto a cidade antiga. Tende a romper os antigos núcleos, apoderando-se deles. O que não impede a extensão do fenômeno urbano, cidades e aglomerações, cidades operárias, subúrbios.

Instaura-se, dessa forma, um duplo processo em três aspectos: industrialização e urbanização, crescimento e desenvolvimento, produção econômica e vida social. Acontece, no entanto, segundo o autor, um choque violento entre a realidade urbana e a realidade industrial.

Há, portanto, uma contradição permanente na realidade urbana, qual seja, a cidade sem urbanização é pobre em termos de concentração de dinheiro e poder político. $\mathrm{O}$ autor cita como exemplo a cidade de Atenas na Grécia. O lugar, antes com certo ar aristocrático em termos de centro de sabedoria, contemplação e cultura, converteu-se num local de peregrinação estética e de consumo turístico. O paradoxo é que o centro organizacional continua forte. No entorno da cidade, aglomeram-se bairros recentes, desorganizados, povoados, segundo o autor, de gente sem raízes. Sem a industrialização, o crescimento populacional é puxado pela indústria do turismo e pela especulação imobiliária; o solo urbano converte-se em mercadoria estabelecendo uma relação perversa entre um fictício desenvolvimento e a convergência da população para a cidade.

\section{O TECIDO URBANO}

Lefebvre (1991b) alerta que o uso do conceito ecossistema para explicar a ordem sistêmica de uma unidade constituída ao redor de uma ou de várias cidades, antigas ou 
recentes, corre o risco de perder o essencial, ou seja, a sociedade urbana que aí emerge constituindo uma nova morfologia. Sennett (1994) trabalha essa questão do tecido urbano, considerando que o mesmo não é feito só de pedra (edificações) nem só de carne (as pessoas), mas que ambos compõem essa morfologia. Para Lefebvre (1991b), o tecido urbano é o suporte de "um modo de viver que pode ser intenso, vivo ou degradado. Mais que uma metáfora, o tecido urbano não é 'um tecido humano' jogado sobre um território geográfico". O espaço geográfico torna-se território justamente na medida em que a vida social aí se faz. Os modos de viver que aí são gestados comportam sistemas de valores, sistemas culturais e um intricado jogo de poder que se expressa na luta pela posse do espaço urbano, do solo urbano e pelas possibilidades de obtenção, ou não, de bens materiais e imateriais. A cidade estabelece outra racionalidade, que é a estratégia de prover a vida urbana. A cidade necessita de uma organização mínima que cumpra certas exigências para a vida em comum: trabalho, serviços de saúde, ensino, cultura e segurança.

Para Lefebvre, o tecido urbano é perpassado por ilhas de ruralidades. Para ele, um europeu francês, essas ilhas são povoados de camponeses envelhecidos. Para uma realidade latino-americana, por exemplo, não se pode considerar que nossa ruralidade seja povoada somente de camponeses envelhecidos. O grande capital, no caso brasileiro, para citar um exemplo, desloca-se para o campo com alta tecnologia, tanto no seguimento da agricultura como no da pecuária, destruindo a natureza, tomando as terras dos índios e ameaçando a agricultura familiar que, segundo o IBGE, é a que mais produz o alimento que chega à mesa dos brasileiros. $\mathrm{O}$ poder do agronegócio perpassa $\mathrm{o}$ tecido urbano, porque é na cidade que se instalam os grandes escritórios dos grandes produtores rurais, os grandes laboratórios de apuro genético para a pecuária, os bancos que movimentam o dinheiro dessa atividade e os escritórios de exportação dos produtos agrícolas.

No entanto, certas partes do Brasil, como o sertão nordestino e o interior da Amazônia, são carentes de tudo. Dessa forma, não podemos analisar o processo de construção das cidades latino-americanas da mesma maneira que se analisam as cidades europeias, como faz Lefebvre. Até porque, aqui, o processo de industrialização começou muito mais tarde.

O tecido urbano tem sua historicidade. Lefebvre (1991b) nos alerta sobre o uso inadequado do termo sociedade industrial, porque o termo não evidencia relações sociais constitutivas do processo de urbanização, uma vez que tal processo não se dá 
apenas pela produção material, mas pelas relações sociais, pelas relações sociais de produção e pela sua historicidade. Mesmo assim, o autor emprega esse termo.

O processo de urbanização, segundo o autor, resulta da sociedade industrial. A tese de Lefebvre é que o processo de urbanização e sua problemática "modificam profundamente a problemática originada do processo de industrialização" (LEFEBVRE, 2008, p. 80). O raciocínio que o autor faz é essencialmente dialético ao explicar que o processo de urbanização não é uma mera consequência exterior ao processo de industrialização. Seria decorrente de um salto qualitativo, que resultou de um salto quantitativo da produção econômica.

Para ele, é um erro teórico e prático afirmar que a racionalidade empresarial, que é uma experiência da industrialização, possa oferecer modelos e esquemas aplicáveis à realidade urbana em formação. Aqui o autor entra com o conceito de racionalidade urbana, que vem culminar com o conceito de sociedade urbana, o qual não pode ser empregado para todo tipo de concepção de cidade. Na perspectiva de Lefebvre, o conceito designa uma realidade em formação. Para ele, a cidade nunca está acabada.

Para elucidar essa tese, Lefebvre divide o tempo histórico em era agrária, era industrial e era urbana. Mesmo considerando essa divisão relativa, dada a complexidade da realidade de um mundo que se faz constantemente, o autor é enfático ao considerar que o processo de urbanização é a construção constante e dialética da própria cidade.

Para o autor, a cidade é um objeto espacial. Com a categoria de espaço, ele indica um campo de estudo complexo em que estão incluídas as dimensões econômicas, demográficas, políticas, entre outras. Se a cidade é um espaço que se abre tanto na dimensão geográfica quanto na social, ela cria lugares que o autor chama de espaços específicos bem distintos do espaço rural. A mediação entre esses dois espaços são as relações de produção que estabelecem a divisão social do trabalho no interior da sociedade. A cidade enquanto tal é uma mediação entre uma ordem próxima e uma ordem distante. A ordem próxima seria o espaço urbano no qual se estabelecem os conflitos de classe, os jogos de poder, o que influi e organiza esse espaço. A ordem distante é dada pelo modo de produção de cada época histórica, que caracteriza as cidades como feudal, escravagista e capitalista.

O autor enxerga a cidade como obra, uma obra de arte, porque para ele a cidade não é somente um espaço intuído e modelado. Aqui o autor vai se referir à construção de uma morfologia urbana não apenas composta por edificações, mas pelos próprios 
corpos dos citadinos que vão construir um espaço urbano, o qual reflete suas expressões estéticas, sua ideologia.

Em “Cidade e Meio Ambiente”, Gonçalves e Souza (2010) fazem uma análise do espaço urbano de Curitiba, Brasil. Enquanto Prosser (2010), ao analisar 1.200 grafites, mostra toda a percepção dos moradores desta cidade por meio daquela modalidade de arte.

Lefebvre refere-se a monumentos, monumentalidade, como um aspecto essencial da cidade enquanto obra. Os significados urbanos são dados pela corporificação dos sentidos que as pessoas dão ao espaço público da cidade. Seus afetos, seus sentimentos de pertença, sua história, geralmente concretizados nas obras de arte, no contexto do pensamento desse autor, fazem nos monumentos um apelo à história da cidade, um apelo à lembrança, à memória.

\footnotetext{
As imagens da cidade povoam o cotidiano da vida urbana. Quando as observamos, fazemos uma observação analítica para distinguirmos as imagens dentro das imagens. Dizendo de outro modo, é possível transformar a imagem numa outra categoria de análise do fenômeno urbano (GONÇALVES, 2006, p. 39).
}

\section{O ESPAÇO SOCIAL EM LEFEBVRE}

Para Lefebvre (1991b), o espaço é um produto social que se constrói dialeticamente, por isso expressa as contradições da sociedade. O espaço social, para o autor, é concebido e construído sempre seguindo a lógica da produção e, nessa lógica, segue uma racionalidade. Os espaços construídos nessa lógica do modo de produção capitalista seguem uma padronização dessa racionalidade.

Para Souza (2006), um estudioso de Lefebvre, os espaços são abstratos, descolados da realidade, primados pela razão estética e pela força das imagens; são construídos pelos "fazedores oficiais da cidade", arquitetos, engenheiros e planejadores urbanos. O espaço urbano é vivido por todos os citadinos e planejado pela tecnocracia capitalista que o redesenha geograficamente, determinando os espaços dos ricos e os espaços dos pobres. Os espaços da produção e do consumo também seguem essa lógica e configuram, segundo o pensamento de Lefebvre, o espaço como uma mercadoria.

O espaço social, portanto, pode auferir a emancipação ou a alienação humana por meio da dialética espacial. Pois, para Lefebvre, se há um espaço geográfico material, também há outras dimensões do espaço desde o espaço mental (concebido, 
percebido, representado) e o "espaço social construído, produzido, projetado, portanto, notadamente o espaço urbano, isto é, o espaço da representação e a representação do espaço" (LEFEBVRE, 2008, p. 40).

\begin{abstract}
A dialética entre o espaço concebido e o espaço vivido se materializa no momento em que as temporalidades e as espacialidades ligadas à irredutibilidade do uso se fazem presentes na apropriação da cidade. O cotidiano desses lugares designa a atividade criadora por meio da construção individual e coletiva dos seus moradores diante da reprodução do espaço (SOUZA, 2009, p. 4).
\end{abstract}

Segundo Souza (2009), Lefebvre define, a partir dessa percepção, três momentos da produção social do espaço:

1- Por concepção do espaço o autor entende a representação abstrata do espaço hierarquizado, imóvel, distante. Com isso Lefebvre quer mostrar a separação que a ciência positivista faz entre sujeito e objeto que, na discussão sobre o espaço, traduz a separação entre o mundo das ideias e o mundo real.

2- Coloca a percepção do espaço como uma intermediação da ordem distante e da ordem próxima, ou seja, as relações específicas de cada formação social vão determinar a maneira como os sujeitos se relacionam com esses dois mundos: o real e o das ideias.

3- O espaço vivido refere-se ao modo de vida real, às estratégias e às costuras que o sujeito e/ou os grupos sociais fazem para viver sua vida cotidiana por meio do enfrentamento, entre o programado e o realmente vivido.

A dialética entre o espaço concebido e o espaço vivido caracteriza a dinâmica da apropriação do espaço urbano numa perspectiva de temporalidade e espacialidade. Isso traduz que a sociedade urbana toma corpo e forma, contundentemente, no espaço da cidade. Gonçalves (2007), em sua pesquisa sobre a apropriação da cidade, realizada em um bairro pobre da periferia da cidade de Criciúma, Santa Catarina, Brasil, constata que os moradores desse bairro concebem o espaço urbano como sendo o centro urbanizado de Criciúma, com suas luzes, praças e calçadas. Esta, para eles, é a cidade desejada. O bairro em que vivem não faz parte da cidade. Consideram que estão à margem dela.

\title{
O CONCEITO DE COTIDIANO EM LEFEBVRE
}


Para Lefebvre (1980), o cotidiano é um fenômeno da sociedade moderna. Ele contrapõe esse conceito de cotidiano ao de estilo característico das sociedades antigas e tradicionais, o qual se traduzia numa organização coerente da vida. Já a característica da vida na sociedade moderna é, em si, contraditória, porque possui riqueza e miséria. $\mathrm{O}$ processo de construção da sociedade capitalista industrial, o cotidiano da vida urbana, seguiria uma política de organização segundo uma lógica da ideologia da classe dominante e, portanto, constitui-se numa estratégia de dominação e hegemonia dessa classe.

Lefebvre afirma que essa é uma tendência internacional dos países capitalistas após a Segunda Guerra Mundial. O autor retoma sua crítica ao conceito de sociedade industrial e às definições de sociedade tecnocrática e sociedade de consumo ao supor que o consumismo, principalmente, é um produto da propaganda que associa imagens ao produto, criando falsas necessidades.

Na perspectiva de Lefebvre (1991b), o domínio e o controle do espaço se constituem numa fonte de poder sobre a vida cotidiana. Esse poder, articulado com outras formas de poder social, controla o espaço social. Mas esse espaço controlado também é um meio de produção de controle, na medida em que engendra as mais diversas formas de controle da vida cotidiana, estabelecendo normas e regras de comportamento, esquadrinhando as pessoas, catalogando-as e disciplinando-as, tal como diria Foucault (2002) em seu conceito de sociedade disciplinar na obra "Vigiar e Punir". Produz também um poder social, estabelecendo o controle do tempo, o tempo da produção, da circulação e do dinheiro.

É no fragmento de tempo do processo repetitivo produzido pelo desenvolvimento capitalista, o tempo da rotina, da repetição e do cotidiano, que essas contradições fazem saltar fora o momento da criação e de anúncio da História, o tempo do possível, o qual, justamente por se manifestar na vida cotidiana, parece impossível. Esse anúncio revela ao homem comum, na vida cotidiana, que é na prática que se instalam as condições de transformação do impossível em possível (MARTINS, 2008, p. 57).

É no cotidiano que as forças de acomodação e resistência, elementos constitutivos do conflito que se estabelece no espaço social, transformam o espaço em território. O conceito de território aqui é colocado como o espaço transformado e gestionado pelos vários poderes que se estabelecem e medeiam as relações sócias na sociedade urbana. Na concepção de Lefebvre (1991a), o cotidiano é o produto histórico 
e o espaço mais próximo de nós. Também se constitui como mediação entre o particular e o universal, ou seja, entre a vida privada e a vida pública, coletiva.

Para este autor (1991b), a participação da sociedade por meio do fortalecimento dos processos participativos, como os movimentos sociais, é fundamental para que as práticas sociais ultrapassem os limites da repetição e se constituam, de fato, em práticas inventivas e libertadoras.

\section{CONSIDERAÇÕES FINAIS}

A estratégia do capitalismo atual é transformar o espaço urbano em lócus de hegemonias sociais e "estetização" da forma e paisagem urbana. A intenção é vender espaços de bem-estar e segurança, como acontece com os chamados condomínios fechados, que se edificam nas grandes e médias cidades do mundo, inclusive no Brasil. Porém, as radicais contradições se expressam na reiteração da segregação urbana, que se expressa na suprema gentrificação da cidade ante a crescente pauperização econômica de grande parte da população mundial.

O capitalismo gera desigualdades, principalmente nos países do sul, ou seja, nos mais pobres, e alimenta o desenho urbano, produz disputas entre os habitantes da periferia (onde a violência de toda ordem se estabelece), num território tomado pelos pobres que trabalham e pelos pobres que traficam drogas, originando, assim, uma paisagem urbana consumista, violenta e desigual.

A chamada revitalização dos espaços urbanos decadentes é um exemplo de desigualdade espacial quando esses projetos confirmam a discriminação ao fazerem espaços para os ricos (turistas), que vêm comprar as "mercadorias turísticas", e os locais dos que seguem sua vida num espaço inóspito, sujo, sem conforto, contando somente com a sorte e sua tradição. Um exemplo clássico, no Brasil, é o mercado Ver-o-Peso, na cidade de Belém do Pará. Esse mercado revitalizado, com suas tendas e espaços clean, termina na porta de vidro que se abre ao mercado popular, local aonde os comerciantes que chegam de barco vendem seus condimentos e limpam seus pescados, os quais ficam expostos às moscas em um ambiente que se confunde com os pregões dos vendedores, com o ir e vir dos turistas e compradores. Os "turistas compradores" gostam do exótico, do original? Segundo Barbosa, constitui-se um arquétipo de cidade pós-moderna, um clichê do capitalismo financeiro. Singapura é um dos exemplos mais emblemáticos, assim como Dubai, nos Emirados Árabes. 
Novos territórios surgem na paisagem do mundo globalizado. A dimensão produtiva ordenada pelas redes e circuitos do capital ordena novos espaços produtivos, tanto materiais como imateriais. Os mercados locais enfrentam-se cotidianamente com os mercados internacionais que se materializam por meio das ressignificações das formas de consumo, da aglomeração urbana, da apropriação do meio natural e das cadeias produtivas industriais. Isso configura um novo espaço sociotécnico em surgimento, o qual vem favorecer o desdobramento da questão urbana para um contexto social com uma complexidade diferente da época em que se desenvolveu o processo de industrialização.

Diante de uma realidade complexa, exige-se, também, um pensamento científico complexo que dê conta das múltiplas faces da realidade urbana. Acredita-se que o pensamento dialético venha contribuir para a construção de metodologias no campo das pesquisas sobre o urbano e para a prática interdisciplinar.

\section{REFERÊNCIAS}

DEMO, P. Metodologia científica em ciências sociais. 2 ed. São Paulo: Atlas, 1989. FOUCAULT, M. Vigiar e Punir. Rio de Janeiro: Vozes, 2002.

GOLDENBERG, M. A arte de pesquisar: Como fazer pesquisa qualitativa em Ciências Sociais. 9 ed. Rio de Janeiro: Record, 2005.

GONÇALVES, T. M. A Cidade como Palco da Urbanidade. In: GONÇALVES, T. M.; SANTOS, R. dos. Cidade e Meio Ambiente: Estudos Interdisciplinares. Criciúma: UNESC, 2010, p. 13-17.

GONÇALVES, T. M. Cidade e Poética. Ijuí: UNIJUÍ, 2007.

GONÇALVES, T. M. Ensaio sobre pesquisa qualitativa. Criciúma: UNESC, 2006.

HABERMAS, J. Pensamento Pós-Metafísico. Rio de Janeiro: Tempo Brasileiro, 1990.

LEFEBVRE, H. A vida cotidiana no mundo moderno. São Paulo: Ática,1980.

Espaço e Política. Belo Horizonte: UFMG, 2008.

. O direito à cidade. São Paulo: Moraes, 1991a.

. The producin of space. Mielen: Blackwel,1991b.

MARTINS, J. S. A sociabilidade do homem simples. São Paulo: Contexto, 2008.

PROSSER, E. S. O Meio Ambiente e o Graffiti em Curitiba-PR (2004-2009). In: GOnÇAlves, T. M.; SANTOS, R. dos. Cidade e Meio Ambiente: Estudos Interdisciplinares. Criciúma: UNESC, 2010, p. 286-346.

SENNETT, R. Carne e Pedra. Rio de Janeiro: Record, 1994.

SOUZA, M. L. de. Mudar a cidade: uma introdução ao planejamento e à gestão 
urbanos. 4 ed. Rio de Janeiro: Bertrand Brasil, 2006.

SOUZA, M. L. Território da divergência (e da confusão): em torno de imprecisas fronteiras de um conceito fundamental. In: SAQUET, M.A; SPOSITO, E.S. Territórios e Territorialidades: teorias, processos e conflitos. São Paulo: Expressão Popular, 2009, p. 38-57. 